\title{
Espirais para pensar temas, perguntas e procedimentos metodológicos em pesquisa: Sobrejustaposições na interface corpo/educação/visualidades
}

\section{Spirals to think issues, questions and methodological procedures in research: overjuxtapositions in the interface body/education/visualities}

\author{
Cristian Poletti Mossi ${ }^{i}$
}

\begin{abstract}
Resumo
O artigo busca, inicialmente, lançar mão de uma visualidade para falar de pesquisa em educação - a intervenção artística Espiral do Conhecimento de André Dalmazzo tentando operar com tais campos no que tange às temáticas, perguntas e procedimentos metodológicos com os quais nos relacionamos constantemente em empreitadas investigativas. Na materialidade da trajetória formativa e da atual investigação de um dos autores, o artigo busca operar com alguns conceitos sobrejustapostos na interface corpo/educação/visualidades. A composição com sobras resultantes de experiências formativas e de pesquisa é assumida como procedimento que institui um complexo capaz de colocar o pensamento em funcionamento em encontros produtivos.
\end{abstract}

Palavras-chave: Metodologia, Pesquisa, Educação.

\begin{abstract}
The paper initially aims at making use of a visuality to talk about research in education the artistic intervention "Spiral of Knowledge" by André Dalmazzo - attempting to operate such fields in relation to issues, questions and methodological procedures with which we interact constantly in investigative endeavors. Within the materiality of the formative trajectory and the current research by one of the authors, the paper seeks to operate with some concepts overjuxtaposed in the interface body/education/visualities. The composition with scraps resulting from research and formative experiences is assumed as procedure that establish a complex capable of putting thought into operation in productive meetings.
\end{abstract}

Keywords: Methodology, Research, Education.

\section{Espiralando um começo}

Não é novidade afirmar que a relação entre tema, perguntas e procedimentos metodológicos em pesquisa é um imbricamento complexo, já que não apresenta soluções únicas. Isto se dá, tendo em vista a própria engrenagem da natureza investigativa, a qual nos lança a terrenos movediços, de incompletudes e sinuosidades, onde não conseguimos firmar os pés no chão e dá-los por assentados por muito tempo. Implicados por temáticas e perguntas investigativas e, desse modo, na procura de procedimentos metodológicos a fim de responder minimamente tais indagações, colocamo-nos em movimentos constantes de incompreensões. Quando se trata de, como neste artigo, tentar unir campos que por si só já carregam traços de acirradas discussões e diferentes pontos de vista já que, ora convergem, ora se distanciam - como é o caso do campo da educação e das visualidades - essa tarefa pode se tornar ainda mais complexa. 
Colocar esses dois campos [educação e visualidades] em um estado de diálogo, tensão e movimento para pensar o que podemos aprender com ambos para e em nossas investigações no que concerne às suas temáticas, questões e posturas metodológicas, se trata de ultrapassar mutuamente dois domínios que nos provocam a inúmeras indagações, especialmente no contexto atual, quando temos repensado as histórias da educação, bem como suas inserções nas sociedades e nas culturas diversas e, da mesma forma, buscado outros lugares para nos relacionarmos com as visualidades enquanto dispositivos de subjetivação e lugares de sobreposição de camadas perceptivas, significativas, temporais, entre tantas outras.

Para tanto, de antemão proponho, como fio condutor - problematizador - desta fala traduzida em escrita, uma espécie de percurso na contracorrente, como que uma espiral desenhada de dentro para fora (e não de fora para dentro), a qual se abre em infinitas injunções. Assim, lançarei mão de uma visualidade para falar de pesquisa em educação e não de pesquisas em educação que tratam de visualidades, tentando operar com tais campos no que tange às temáticas, perguntas e procedimentos metodológicos com os quais nos relacionamos constantemente. Desse modo, utilizarei algumas imagens de registro da intervenção "Espiral do Conhecimento" construída na Sala Azul do Centro de Educação (CE) da Universidade Federal de Santa Maria (UFSM), no Rio Grande do Sul ${ }^{1}$. Este trabalho foi uma experiência vivenciada por mim em uma das disciplinas cursadas no primeiro semestre do ano de 2011, o Seminário de Tese I, proposta pelo colega também participante da disciplina André Dalmazzo, sala esta onde geralmente ocorriam os encontros, às terças-feiras pela manhã, quinzenalmente.

Inúmeras foram as reflexões que este trabalho me provocou, assim como as discussões que o mesmo gerou em sala de aula nos encontros subsequentes. Tentarei, ainda que minimamente, pontuar algumas delas no decorrer deste texto, colocando em pauta, inclusive, minha vivência como pesquisador.

Afinal, o que significa fazer pesquisa no campo da educação e das visualidades nos dias de hoje? O que implica a escritura de um trabalho científico/acadêmico na atualidade? Como se dá a filiação a correntes de pensamento que nos permitem defender nossas ideias? E quais as conseqüências [no meio acadêmico] de novos formatos de [fazer] pesquisa que não os que já conhecemos?

$1 \quad$ Este texto foi inicialmente escrito para a disciplina Seminário de Tese I, do Programa de PósGraduação em Educação (PPGE), do Centro de Educação (CE) da Universidade Federal de Santa Maria (UFSM) onde desenvolvo meus estudos de doutoramento sob a orientação da Profa. Dra. Marilda Oliveira de Oliveira, com financiamento integral da CAPES. 
A fim de tentar fomentar mais indagações para tais questionamentos, sem a pretensão de respondê-los e dá-los por assentados, mas sim de provocá-los a muitas mais possibilidades interpretativas, a seguir conto sob o meu ponto de vista como foi minha inserção à intervenção "Espiral do Conhecimento" em uma disciplina que trata justamente de pesquisa no campo da educação. Na sequencia falo um pouco da pesquisa que venho desenvolvendo em minha tese de doutorado e assim dos meus próprios temas, perguntas e posturas metodológicas, de momento assumidas, para posteriormente tentar construir algumas pontes entre ambas: construção esta com o que resta, com o que sobra mediante a intersecção das duas.

\section{Sobre obstáculos imaginários, verdades inventadas e problemas epistemológicos que são de linha e plástico}

"Sou o que está diante de mim."

(GUATTARI, 1992, pp.28-29)

O outono começava já a soprar suas primeiras brisas, lembro-me que usava algum tipo de agasalho leve. Passei na cantina do prédio para pegar um café e logo me dirigi à Sala Azul do Centro de Educação da UFSM para a aula de Seminário de Tese I. A porta da sala ainda estava fechada e em frente a ela os colegas e um dos professores da disciplina aguardavam enquanto alguém trazia a chave para entrarmos e começarmos mais um dia de atividades. Percebi que o colega André Dalmazzo permanecia encostado na parede e segurava uma câmera fotográfica nas mãos, mas nem imaginei que algo fora do previsto poderia acontecer por obra dele minutos após.

Ao abrirmos a sala (quando finalmente alguém chegou com a chave da mesma) nos deparamos com uma intervenção construída com inúmeros copos plásticos brancos com a boca virada para baixo cuidadosamente organizados em forma de espiral no chão e fios de lã que se cruzavam sobre os copos plásticos e estavam amarrados nas cadeiras as quais circundavam a sala.

A primeira reação da turma foi de imensa surpresa e de dificuldade em encarar aquilo que se mostrava diante de nossos olhos. Chegamos até a pensar em procurar outra sala para ter aula, com a justificativa (que, é claro, não era suficiente) de não desmanchar a intervenção. O que aqueles copos faziam organizados naquele lugar? Estariam dispostos para nossa aula, ou teríamos nós entrado na sala equivocada? O que copos plásticos e fios de lã estariam fazendo numa sala de aula dispostos daquela maneira? O que copos plásticos e fios de lã poderiam ter a ver com pesquisa? O que tinham a ver conosco, acadêmicos buscando um título de doutorado em Educação? 


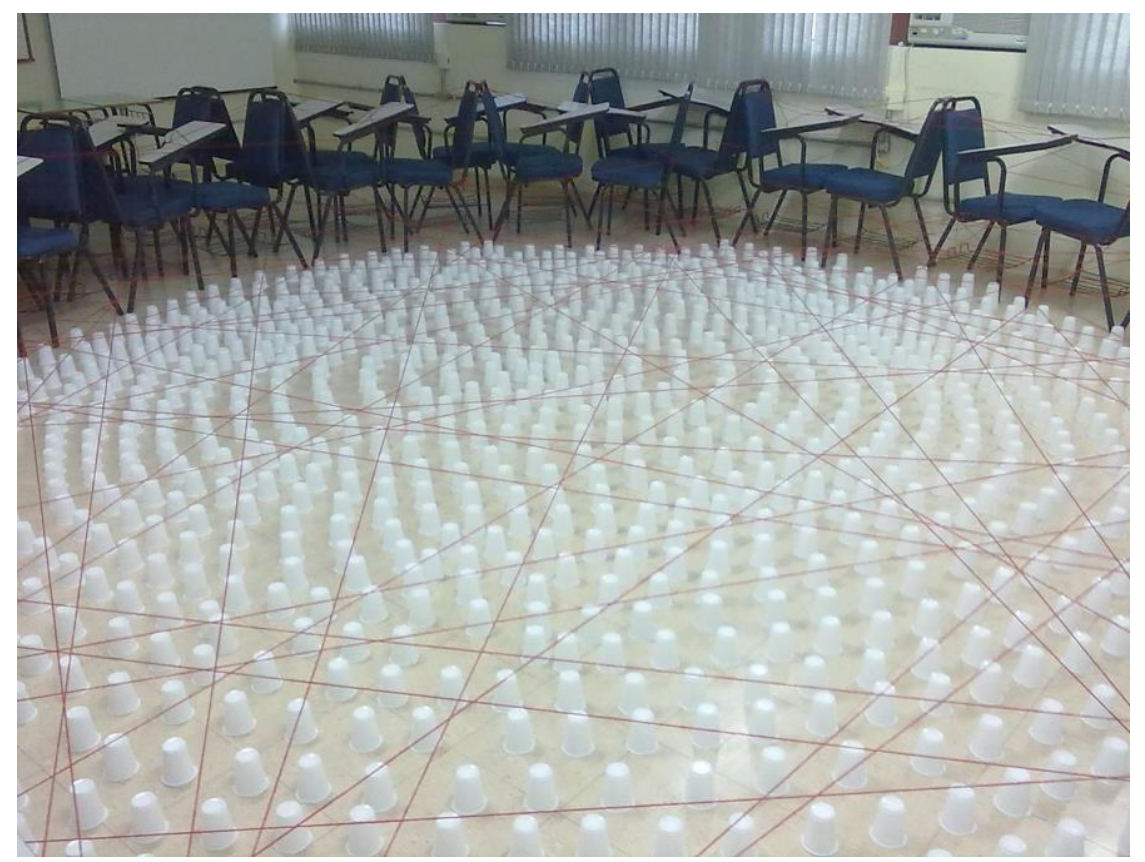

Figura 1: Registro fotográfico da intervenção 'Espiral do Conhecimento', arquivo pessoal do autor.

Para mim ao menos, muita coisa...Primeiro pela questão do enfrentamento, do incômodo causado. Toda pesquisa, toda investigação é um enfrentamento, gera enfrentamentos, nos incomoda e desacomoda. Enfrentamos nossos objetos e problemas de pesquisa e tal enfrentamento na maioria das vezes não é pacífico. Brigamos com eles, e essa briga deixa em nós inúmeras marcas que sim, sem dúvida, cicatrizam com o tempo e dão espaço para outras tantas marcas que serão adquiridas nas várias outras brigas/pesquisas que nos depararemos vida a fora.

Essa 'briga' tem a ver não só com enfrentamento, mas também com defesa. Defesa de propósitos, de ideais, de crenças. Posturas e perspectivas que podem [e devem] ser revistas com o passar do tempo. Num tempo em que os horizontes mudam constantemente, nenhuma briga deve durar infinitamente, senão se torna cega, sem ao menos promessa de chegada, ainda que saibamos que essa chegada é provisória. É preciso perder-se para encontrar a direção. E as direções são muitas.

Nossos problemas, esses problemas epistemológicos de que falamos, são obstáculos imaginários, não existem concretamente, mas tomam espaço em nossas vidas, no modo como olhamos as coisas e também como nos olhamos. Uma espiral com copos, atravessada por fios de lã, poderia ter sido naquela manhã quase fria de terça-feira só uma espiral com copos, mas não o foi. Ela foi um obstáculo, concreto sim, mas que 
traçou na Sala Azul do CE inúmeros obstáculos imaginários (mas não menos concretos) para pensarmos o que afinal estávamos fazendo ali, quais eram nossos problemas, nossos projetos de pesquisa. Quais nossos papéis enquanto pesquisadores em Educação. Resolvemos então adentrar a obra, não fugir. Enfrentar o obstáculo que se empunha à nossa frente. O estranhamento com aqueles objetos fora de seu contexto, somado ao medo que geralmente temos da desordem, quase nos fez fechar a porta, virar as costas e procurar outra sala para termos aula. Uma aula provavelmente igual a todas as outras aulas que tivemos até então, ou que ao menos a maioria estaria tendo nas tantas outras salas de aula ao nosso redor. Mas não. Tesouras em punho começamos a cortar os fios e empurrar os copos que obstruíam nosso caminho, unindo-os no centro da sala em outra formatação. Nosso intuito com isso não era o de destruição, mas o de desconstrução. Era o de desconstruir para construir algo diferente, inusitado. Uma nova forma, não prevista, construída com os restos de nossa ação frente à obra.

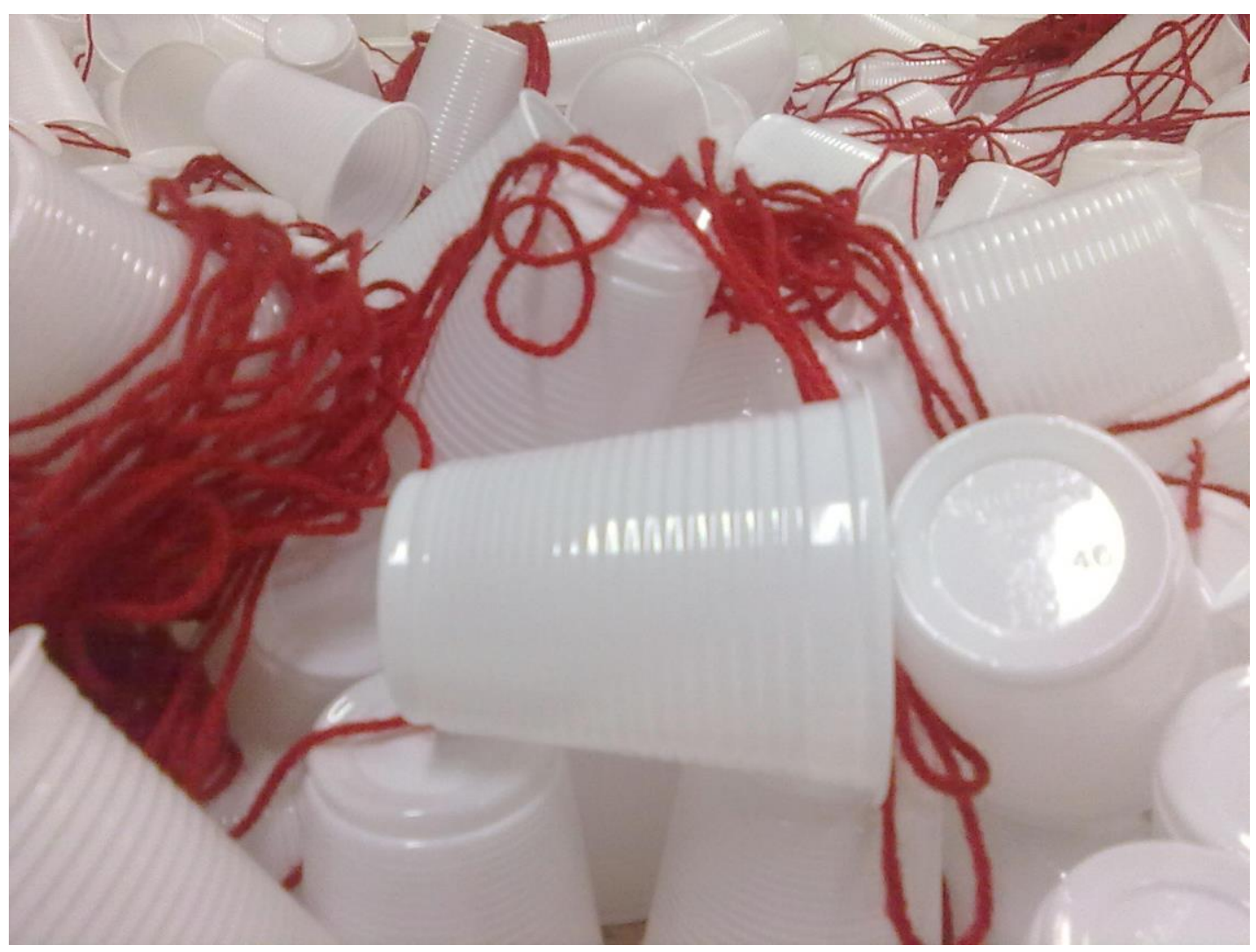

Figura 02: Registro fotográfico da intervenção 'Espiral do Conhecimento' desconstruída, arquivo pessoal do autor.

Em nossas pesquisas, inúmeras vezes, a vontade é de fechar a porta e ir embora. Procurar um lugar seguro, igual aos tantos outros lugares que estivemos até então. Ou pelo menos seguir em frente sem ser importunado pelos limites, pelas tensões, pelo desconforto gerado na falta de uma ordem. O que por vezes não nos damos conta, é que a tal 'ordem' a que chamamos de normalidade também é uma invenção, uma convenção, 
e que por assim dizer pode ser revista, reinventada e reinterpretada quantas vezes quisermos. E que a desordem, não é nada além do que outra ordem, outra composição. Nesse sentido, é importante repensar o caráter linear/normativo de nossas pesquisas. Procurar outros lugares para olhar/pensar/apresentar nossas investigações, outras posturas frente ao desafio. A questão do adentramento à intervenção com as tesouras, não nos deixou em uma postura passiva à realidade que se empunha a nossa frente. Fez com que nos encharcássemos com ela e assim tivéssemos uma experiência a qual, como diria Bondía (2002), nos acontecesse, passasse a fazer parte de nós.

As pesquisas ditas científicas/acadêmicas tradicionalmente foram construídas dentro de parâmetros de neutralidade e distanciamento aos objetos de investigação, como se isso pudesse garantir uma maior veracidade dos resultados e como se as verdades pudessem ser únicas, universais, inequívocas, irrevogáveis. Contudo, com as inúmeras transformações epistemológicas que vêm sofrendo a ciência, o que temos podido perceber é que as realidades não são tão simples e tão pouco complexas e que aprisionálas em respostas tão diretivas é, de certa maneira, reduzi-las demasiadamente, é castrálas de suas infinitas possibilidades (KINCHELOE \& BERRY, 2007). Vemos o que podemos ver, o que nos é permitido ver em cada momento, conforme os olhos que temos disponíveis, conforme os olhos que buscamos para enxergar.

Como infere Costa (2006, pp.72-73)

Nossas ferramentas teóricas são como óculos, lentes, que nos permitem enxergar algumas coisas e não outras. Nossas perspectivas de análise não nos ajudam apenas a compreender um problema, elas nos ajudam a compor o problema. Ao problematizarmos um determinado campo, objeto ou fenômeno, nós estamos inventando algo novo com as nossas 'lentes'.

Assim, ao pensarmos em outros modos de fazer pesquisa, de apresentar nossas pesquisas, não estamos só buscando dados concretos como também estamos possibilitando a existência desses dados, das realidades com as quais dialogamos. Isso não significa falta de critérios, mas a produção de novos critérios, de novos lugares de fala, de outra produção de sentidos. Significa compreender a complexidade da realidade, mas também sua provisoriedade, assim como se mostrou provisória a aqui comentada "Espiral do Conhecimento". Faz-se necessário romper paradigmas, cortar os fios, arrastar os copos, adentrar a pesquisa como adentrarmos na obra, move-la, produzindo algo a partir do que sobra dessa ação. 


\section{O vir a ser do pesquisador e da pesquisa: que temas, perguntas e procedimentos metodológicos me encantam atualmente?}

Ao situar minhas atuais inquietações investigativas, faz-se importante, a meu ver, primeiramente rememorar um pouco de minha trajetória formativa/acadêmica, no intuito não de justificar, mas de explicitar alguns dos caminhos que me trouxeram até aqui, fazendo-me assim pensar as coisas que penso hoje e preocupar-me com as questões que hoje me preocupo.

Minha trajetória sempre foi constituída a partir do atravessamento de inúmeros caminhos que não necessariamente passaram diretamente pelo campo da Educação enquanto área do conhecimento, contudo hoje percebo que sempre estiveram de algum modo contaminado, afetado por ela.

Fiz graduação em Desenho e Plástica - Bacharelado e, logo depois, ingressei por uma seleção interna que havia nesse mesmo curso a fim de dar seguimento às disciplinas da Licenciatura nessa área. Este fato, embora possa parecer ínfimo, ocasionou em mim um tipo de formação muito específica no qual primeiramente me tornei bacharel, com uma alta carga horária em ateliês de práticas em linguagens artísticas, para posteriormente pensar em uma carreira docente, vinculada ao ensino e à pesquisa. Ou seja, me formei primeiramente "artista" ${ }^{2}$ para posteriormente ser professor, dentro de uma lógica ainda bastante ligada aos currículos de arte modernistas, que prevaleceram no Brasil desde a segunda metade do século passado, de que prática e teoria eram coisas diversas considerando que a primeira seria proveniente da segunda - e que, por assim dizer, saber 'fazer' também significaria saber 'ensinar'. Que saber 'ensinar' seria um resultado do saber 'fazer's.

Dando seguimento à minha formação, cursei uma especialização em Design para Estamparia, onde trabalhei por um tempo com a área de moda, ainda muito focado na prática artística e nos processos criativos oriundos do trabalho em ateliês, ingressando mais tarde no Mestrado em Artes Visuais com um trabalho no campo da História, Teoria e Crítica de Arte.

\footnotetext{
2 Utilizo tal expressão entre aspas simples por entender que no atual sistema social/cultural/histórico que atuamos, um curso de graduação não é o único pré-requisito para alguém ser entendido enquanto artista em nossa sociedade ocidental, há inúmeras outras questões que atravessam essa profissão atualmente para que a mesma seja legitimada como tal.

A escola alemã de arquitetura, artes plásticas e design conhecida por Bauhaus, que teve grande atuação na Alemanha do início do século XX foi uma forte influência para alguns currículos de arte de todo o mundo, inclusive do Brasil.
} 
Nesse último, propunha-me a pensar entrelaçamentos a partir de duas obras das artistas contemporâneas Claudia Casarino e Vanessa Beecroft, as quais trazem respectivamente vestes sem corpos e corpos sem vestes na poética de seus trabalhos. Neste estudo me propus a discutir, a partir das vestes, corpos e de suas respectivas ausências e presenças, os conceitos de territorialidade (entendendo o corpo e as vestes como tais), bem como pensar as possibilidades de imbricamento entre as poéticas das artistas citadas, o que chamei em minha dissertação ${ }^{4}$ de sobrejustaposições ${ }^{5}$. Durante este trabalho, produzi um diário visual baseado no conceito de diagrama ${ }^{6}$ trazido por Basbaum (2007), o qual fazia uso de palavras e imagens para propor conotações pessoais acerca das temáticas utilizadas pelas artistas e das obras propostas.

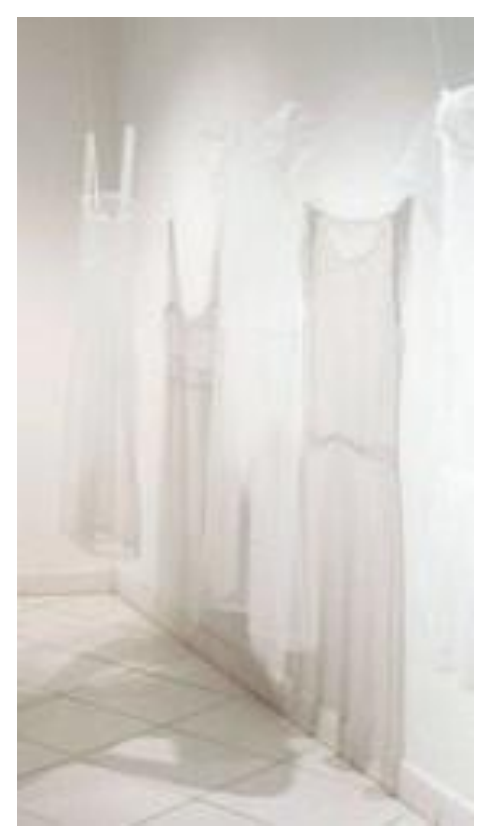

Figura 03: Claudia Casarino, sem título Objeto/Instalação, detalhe, 2005 Fonte:

http://claudiacasarino.com/index.html

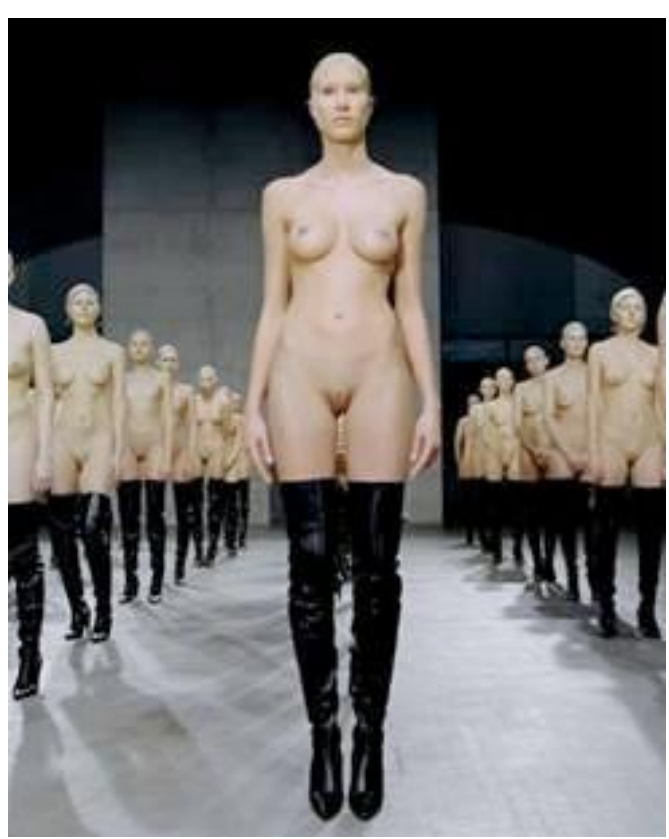

Figura 4: Vanessa Beecroft, vb 45 Performance, detalhe, 2001 Fonte:

http://www.vanessabeecroft.com

Em setembro do mesmo ano, fui aprovado como professor substituto do Departamento de Metodologia do Ensino (MEN) do Centro de Educação (CE) dessa mesma instituição,

\footnotetext{
4 Dissertação intitulada 'Possíveis territorialidades e a produção crítica da arte - suturas e sobrejustaposições entre vestes sem corpos e corpos sem vestes', concluída e defendida em março de 2010. 5 Noção/palavra construída a partir da licença poética resultante da união das palavras sobreposição e justaposição.

Diagrama enquanto "um tipo de esquema visual" que "sempre junta palavras e imagens, utilizando recursos gráficos para criar um dispositivo visual". Basbaum (2007, p.61) infere que "toda vez que o espectador é capturado pelo trabalho em um campo de intensidades, um diagrama pode ser traçado/desenhado, materializando este processo, este devir (...). Assim, diagramas desempenham o importante papel de conectar, mediar, relacionar, associar - não de um modo passivo (...) mas de uma forma dinâmica e ativa (...) - matérias que se revestem de heterogeneidade, indicando e construindo regiões de contato".
} 
onde trabalhei basicamente com formação inicial de professores da área das licenciaturas em artes visuais, pedagogia e educação especial.

Foi inevitável durante tal experiência, trazer conceitos que estava pensando durante a construção de minha dissertação para minha prática na formação docente em artes visuais e, do mesmo modo - e como um contraponto - pensar as imagens das obras que estava problematizando em meu trabalho de mestrado com um olhar proveniente de minha vivência enquanto professor. Ou seja, na primeira discutia a ausência e a presença do corpo e sua relação com as vestes (do mesmo modo, ausentes e presentes) na poética das obras já mencionadas, produzindo assim um discurso legitimador das mesmas. O que fazia em sala de aula também envolvia corpos que se propunham a um vir a ser professor. Eram corpos conformando-se a partir de práticas e dispositivos específicos lançados por mim e, para tanto, havia de produzir discursos específicos com relação ao campo da docência em artes visuais.

A partir do exposto posso afirmar que, trabalhando entre os campos da história/teoria/crítica e da educação das artes visuais (formação docente), o que constituí foi um desvio em minha formação. Ou seja, produzi possibilidades alternativas de caminhos que me fizeram vivenciar tal experiência de um modo muito específico, que não hierarquiza uma área com relação à outra, mas vê possibilidades nas contaminações entre as mesmas.

Atualmente meu projeto de tese possui como problemática central pensar a produção de pesquisas no campo educativo frente à prática do corpo sem órgãos elucidada por Deleuze e Guattari na obra Mil Platôs a partir de Artaud (1947, conferência radiofônica Para Acabar com o Julgamento de Deus). Tal prática, conjura possibilidades para pensar um corpo de intensidade zero, antes do organismo estratificado que, embora precise dele enquanto superfície por onde passam intensidades, não se confunde com o mesmo. Portanto, um corpo antes do corpo, não como essência ou origem, mas como plano onde se imantam possibilidades produtivas as quais procuram se distanciar do já instituído/legitimado. No âmbito da produção de investigações no campo educativo, isso implica pensar que certos temas, perguntas, posturas metodológicas, e até mesmo conformações de espaços, corpos, visualidades, entre outras referências, podem ser repensadas e precipitadas no sentido de um fora onde há somente potências e intensidades (LEVY, 2011), com infinitas possibilidades de outras composições, readequações. 
Desse modo, também trato em meu trabalho de pensar em formas de constituir o corpoinvestigador e o corpo da investigação em meio a escritas e visualidades sobrejustapostas que instauram atmosferas em que o leitor é convidado a trilhar caminhos e sulcar sentidos perante efeitos de superfície (DELEUZE, 2011). Assim, procuro apontar para algo que Pereira (2013, p. 215) menciona em seu texto, alocando que "a escrita é um campo de negociação do qual participam escritor e leitor, ambos em permanente (...) deslocamento no ato articulado (embora diacrônico) de escrever e ler". Esse mesmo autor ainda pondera que, tradicionalmente, a escrita das ciências sobretudo das ciências ditas duras - sempre foi vincada em uma preocupação com os efeitos de verdade em sua construção, ou seja, que ao ler um ensaio científico o leitor pudesse ter, frente a toda uma rede de argumentação, a certeza e a segurança com relação à sua autenticidade e veracidade. Contudo, "chegamos ao final do século XX admitindo que toda ciência é humana e que essas classificações servem quando muito para organizar catálogos de bibliotecas" (PEREIRA, 2013, p. 219).

Nessa perspectiva, não falo de um corpo que é somente orgânico, biológico, mas de um corpo intensivo, um corpo de agenciamentos múltiplos ao modo de Deleuze e Guattari (1996). Interessa-me partir de uma perspectiva onde possa ser pensado que quando aprendo algo, ou quando executo determinada conduta há uma inscrição que fica marcada em mim, no meu próprio corpo (KASTRUP, 2007) e que acabo por incrustar também no contexto à minha volta que não se separa de mim.

Neste caso específico, não estou falando somente de corpos docentes, de corpos pesquisadores, ou ainda de corpos que se tornam docentes/pesquisadores, mas do próprio corpo da pesquisa que agencia múltiplos outros corpos sobrejustapostos escritas, visualidades, eventos, entre outros - possibilitando, como situa Levy (2011) a partir de Deleuze, um complexo capaz de dar outras velocidades ao pensamento, fazê-lo percorrer mapas não representacionais, mas inventivos, produtivos de percursos impensados; tensionar o que é dito (através da escrita) e o que é visto (através das imagens), para assim propor outras dobras, outras linhas de subjetivação; liberar as diagonais presas em sistemas pontuais fixos (DELEUZE, 1997), construir sistemas pontuais simplesmente para fazê-los detonar; perseguir uma escrita enquanto processo de resistência, enquanto busca por um corpo sem órgãos teórico e metodológico dos modos de produzir conhecimento no campo da educação.

\section{Sobre produzir algo com sobras}

Sobras. Há algum tempo tenho pensado que é para isso e a partir disso que produzimos nossas experiências e assim nossas pesquisas. A pesquisa é uma experiência, e a 
experiência produz sobras. O que ficam de nossas trajetórias são sobras que reconfiguramos, que compomos no plano do presente. Nós somos, enquanto pesquisadores, o resultado de sobras, deixamos também sobras pelo caminho, para que tantos outros as ocupem, façam uso delas. A pesquisa é construída com sobras, a partir de sobras, de fragmentos e não deixa senão sobras para outros que virão.

Loddi (2010, p.49) pontua que...

A ideia de fragmento geralmente é do pedaço de alguma coisa que se quebrou, que foi partido. A imagem do fragmentário é algo incompleto, que não está inteiro, acabado, fechado ou concluído. O conceito de fragmento, entretanto, extrapola a dimensão espacial para atingir a dimensão temporal, ou seja, a fragmentação como estado do efêmero, do processo, do descontínuo.

A investigação que estou me propondo a produzir em minha tese de doutorado, os temas, perguntas e procedimentos metodológicos que tenho utilizado não deixam de estar sendo selecionados, constituídos e colocados em funcionamento mediante as sobras de minha trajetória formativa enquanto artista/designer/pesquisador/professor nos campos da educação e das artes visuais, bem como das tantas outras experiências a que venho percorrendo durante os deslocamentos que me dispus a fazer, que meu corpo foi e é submetido, como no caso da que vivi com a intervenção "Espiral do Conhecimento" em uma das disciplinas que estive frequentando, no caso o Seminário de Tese I.

Inúmeras são as leituras, os encontros, os acontecimentos que acoplam o próprio pensamento ao pensar (LEVY, 2011) e colocam-no em funcionamento produtivo. O que resulta de tudo isso? Certamente fragmentos os mais diversos que componho forçosamente, engendro e distribuo no plano aberto da pesquisa.

As visualidades parecem nos convidar para um encontro de outra natureza que a forma escrita, propondo espaços de interlocução que se distanciam da reafirmação de ideias representacionais e/ou ilustrativas, mas percorrem sentidos como ondas que produzem estados de tensão, de friç̧ão.

Quando retomo minha trajetória não a retomo no sentido de dizer $E u$ e me ver como sujeito autônomo em meio aos processos, mas como uma forma impessoal que produz e é produzida em meio a tais encontros com pessoas, ideias, coisas, visualidades. Nesse sentido não falo sobre mim, mas a partir de mim e do que tenho vivido levando em conta os diferentes papéis com os quais negocio e atuo diariamente, a partir das diferentes sobrejustaposições que produzo ao longo de minha formação corpórea/subjetiva que se 
demonstra sempre inacabada. A pesquisa também é corpo, agenciamento de corpos, e pretende também ser para tantos outros que tiverem acesso a ela um reservatório de sobras que possam ser úteis (ou não) para suas próprias trajetórias formativas, para suas próprias investigações.

Quando falo em sobrejustaposições falo de uma prática de produção de sentidos a partir de sobras. Restos, fragmentos de discursividades de diferentes ordens às quais faço uso para me colocar frente ao mundo enquanto artista/designer/pesquisador/professor. Falo de um trajeto, de um método, mas antes de tudo de uma noção que se estabelece sem hierarquizações fixas. Utilizo-a com o fim de dar sentido ao que chega até mim, ao que me proponho vivenciar a partir dos desvios, das possibilidades de caminhos que invento no intuito de 'coletar' e 'transmutar' as sobras e assim dar a vê-las a tantos outros.

Compreendo assim a formação e, por que não, a própria pesquisa - que também é sobra no processo formativo - enquanto algo em constante conjugação. Em constante processo inacabado, aberto às novas possibilidades de imbricamentos diversos, de confabulação de novas (des)ordens.

\section{Referências}

ARTAUD, A. Para acabar com o julgamento de Deus (Pour en finir avec le jugement de dieu [1947]). In: WILLER, C. [tradução, seleção e notas]. Escritos de Antonin Artaud. Porto Alegre: L\&PM, 1983, pp. 145-162.

BASBAUM, Ricardo. Além da pureza visual. Porto Alegre: Zouk, 2007.

BONDÍA, Jorge Larrosa. Notas sobre a experiência e o saber de experiência. In: Revista Brasileira de Educação, nº19, Jan/Fev/Mar/Abr/2002, pp.20-28.

COSTA, Marisa Vorraber. O magistério e a política cultural de representação e identidade. In: COSTA, Marisa Vorraber. O magistério e a política cultural. Canoas, RS: Ed. da ULBRA, 2006, pp. 69-92.

DELEUZE, Gilles. Lógica do Sentido. São Paulo: Perspectiva, 2011.

DELEUZE, Gilles; GUATTARI, Félix. Mil platôs: capitalismo e esquizofrenia, vol. 3. Rio de Janeiro: Ed. 34, 1996. 
Mil platôs: capitalismo e esquizofrenia, vol. 4. Rio

de Janeiro: Ed. 34, 1997.

GUATTARI, Félix. Caosmose: um novo paradigma estético. São Paulo: Ed. 34, 1992.

KASTRUP, Virgínia. A invenção de si e do mundo: uma introdução do tempo e do coletivo no estudo da cognição. Belo Horizonte: Autêntica, 2007.

KINCHELOE, Joe L.; BERRY, Kathleen. Pesquisa em educação: conceituando a bricolagem. Porto Alegre: Artmed, 2007.

LEVY, Tatiana Salem. A experiência do fora: Blanchot, Foucault, Deleuze. Rio de Janeiro: Civilização Brasileira, 2011.

LODDI, Laila Beatriz da Rocha. Casa de bricolador(a): cartografias de bricolagens. Dissertação de Mestrado. Universidade Federal de Goiás (UFG)/Faculdade de Artes Visuais (FAV)-Goiânia/GO, 2010.

PEREIRA, Marcos Villela. Espaço aberto: a escrita acadêmica - do excessivo ao razoável. In: Revista Brasileira de Educação. V.18. n.52. jan-mar. 2013, pp. 213-244.

\footnotetext{
' Doutorando do Programa de Pós Graduação em Educação, Universidade Federal de Santa Maria, Rio Grande do Sul. cristianmossi@gmail.com
}

Recebido em: 23/09/2013

Aprovado em: 15/10/2013 
Revista Digital do LAV - Santa Maria - ano VI, n.11, p. 118-130 - set. 2013 